\title{
THE EFFECT OF THE MgO AGGREGATE SIZE ON THE DENSIFICATION OF SINTERED MgO
}

\author{
ENDONG JIN, JINGKUN YU, TIANPENG WEN, CHEN TIAN, ZHAOYANG LIU, BEIYUE MA, "LEI YUAN
}

School of Metallurgy, Northeastern University, Shenyang 110819, China

"E-mail: yuanl@smm.neu.edu.cn

Submitted August 23, 2019; accepted September 30, 2019

\begin{abstract}
Keywords: Aggregate size, Bulk density, Sintered MgO, Ball milling
$\mathrm{MgO}$ powders with different aggregate sizes were prepared by alcohol ball milling and were sintered at different temperatures. The morphology of the $\mathrm{MgO}$ aggregate, bulk density and section morphology of the sintered $\mathrm{MgO}$ were investigated. The results showed that there was a significant exponential correlation between the average $\mathrm{MgO}$ aggregate size and bulk density, the bulk density of the sintered $\mathrm{MgO}$ increased with a decrease in the average aggregate size. In order to obtain dense magnesia with a bulk density of more than $3.40 \mathrm{~g}^{\cdot} \mathrm{cm}^{-3}$, the average aggregate size should be reduced to less than $3 \mu \mathrm{m}$. The small aggregate size could produce the dense sintered $\mathrm{MgO}$ due to the larger contact area between the aggregates after forming. Furthermore, the sintered $\mathrm{MgO}$ prepared from the small aggregate size had fewer pores and microcracks after sintering, and the sintering temperature had a significant effect on increasing the grain size. In particular, the maximum grain size was more than $40 \mu \mathrm{m}$ under $1600^{\circ} \mathrm{C}$.
\end{abstract}

\section{INTRODUCTION}

Sintered magnesia (also called sintered $\mathrm{MgO}$ ) has drawn attention for its applications in metallurgy as a raw material for alkaline refractories [1]. The properties of the sintered $\mathrm{MgO}$, especially the bulk density and grain size, are important factors limiting the service life and service range of $\mathrm{MgO}$ refractories. In order to obtain $\mathrm{MgO}$ refractories with excellent properties, the bulk density of the sintered $\mathrm{MgO}$ is required to be more than $3.40 \mathrm{~g} \cdot \mathrm{cm}^{-3}$ with a grain size over $40 \mu \mathrm{m}$ [2]. In the traditional process, the bulk density of the sintered $\mathrm{MgO}$ is generally enhanced by increasing the sintering temperature (more than $1800{ }^{\circ} \mathrm{C}$ ) or the moulding pressure of the green body [3]. However, these two measures not only consume a lot of resources, but also increase the cost of the sintered magnesia preparation. Therefore, it is necessary to improve this production process.

Generally, sintered $\mathrm{MgO}$ is prepared by a two-step calcination method [4]. Namely, the $\mathrm{MgO}$ powders are first obtained by calcining magnesite powders under a lower temperature, and the $\mathrm{MgO}$ powders are moulded and then sintered at a high temperature. However, it is difficult to obtain high density sintered $\mathrm{MgO}$ by this method. Some researchers considered that the bulk density of the sintered $\mathrm{MgO}$ was greatly influenced by the properties of the $\mathrm{MgO}$ powders $[5,6]$. Each $\mathrm{MgO}$ particle is composed of a large number of $\mathrm{MgO}$ microcrystals to form an aggregate and this aggregate size is generally about $40 \mu \mathrm{m}$. This $\mathrm{MgO}$ aggregate is also called a pseudomorphic particle which hinders the densification of the sintered $\mathrm{MgO}$ during the sintering process $[7,8]$. In the subsequent work, the researchers have proposed to improve the bulk density of the sintered $\mathrm{MgO}$ by changing the parent salt pseudo phase, such as the method of the light calcining hydration of magnesite [9]. Actually, the $\mathrm{MgO}$ aggregate properties also have a great influence on the bulk density of the sintered $\mathrm{MgO}$, such as the aggregate size. Rhodes reported [10] that the improved performance of the ceramic was probably due to the agglomerate size reduction rather than a reduction of the true crystallite size. Generally, the bulk density of metal oxides increases when decreasing the particle size of the powders due to the increasing sintering driving force when decreasing the particle size. For a long time, people have been devoted to the study of the density of amorphous powders or aggregate powders with a size smaller than $1 \mu \mathrm{m}[11,12]$. Unfortunately, the influence of larger aggregates on the bulk density is ignored.

Hence, in this paper, $\mathrm{MgO}$ powders with different aggregate sizes were prepared by the alcohol ball milling method. After sintering at different temperatures, the effect of the $\mathrm{MgO}$ aggregate size on the densification and microstructure of the sintered $\mathrm{MgO}$ was discussed.

\section{EXPERIMENTAL}

\section{Raw material}

The $\mathrm{MgO}$ powder, used as a raw material, was prepared by calcining magnesite powder (Da Shiqiao, China) at $850{ }^{\circ} \mathrm{C}$ for $1 \mathrm{~h}$. The average aggregate size of the $\mathrm{MgO}$ 
powders is shown in Figure 1 and the composition of the magnesite powders is listed in Table 1 . The average aggregate size of the $\mathrm{MgO}$ powders was $37.9 \mu \mathrm{m}$, and the main impurities were $\mathrm{SiO}_{2}, \mathrm{Al}_{2} \mathrm{O}_{3}, \mathrm{Fe}_{2} \mathrm{O}_{3}$, and $\mathrm{CaO}$.

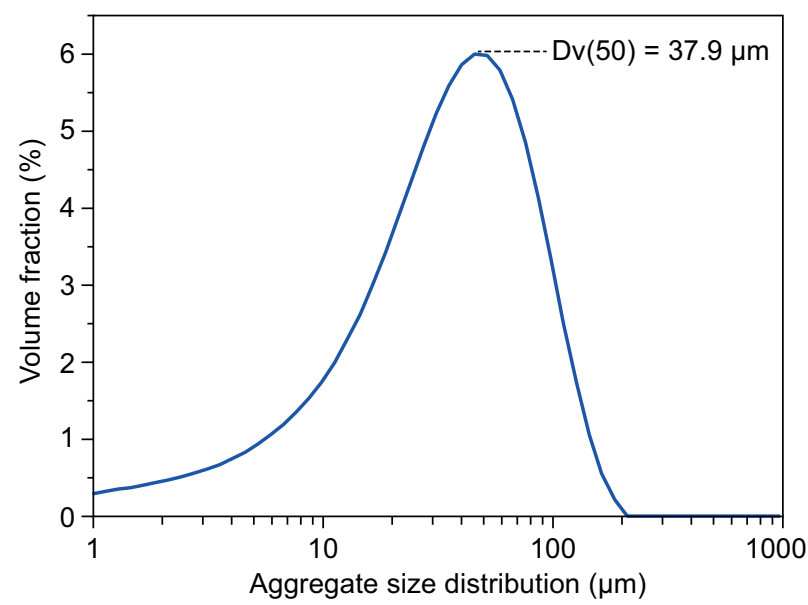

Figure 1. The aggregate size distribution of the $\mathrm{MgO}$ powders.

Table 1. The chemical composition of the magnesite (wt. \%).

\begin{tabular}{cccccc}
\hline $\mathrm{MgO}$ & $\mathrm{SiO}_{2}$ & $\mathrm{Al}_{2} \mathrm{O}_{3}$ & $\mathrm{Fe}_{2} \mathrm{O}_{3}$ & $\mathrm{CaO}$ & I. L. \\
\hline 47.03 & 0.26 & 0.06 & 0.27 & 0.66 & 51.72 \\
\hline
\end{tabular}

\section{Experimental process}

The powders with different average aggregate sizes were prepared by the alcohol ball milling method. The ball milling was conducted in a MC-nylon jar for different times at $500 \mathrm{r} \cdot \mathrm{min}^{-1}$. The experimental ball was an agate ball and the medium was an alcohol. The ballto-powder mass ratio was 5:1. After the ball milling, the mixture of the powder and the medium was dried at $90{ }^{\circ} \mathrm{C}$. The ball milling times were $0.25 \mathrm{~h}, 0.5 \mathrm{~h}, 1 \mathrm{~h}, 2 \mathrm{~h}$, $4 \mathrm{~h}$ and $6 \mathrm{~h}$, respectively. Compression was carried out by using a uniaxial hydraulic press, and the $\mathrm{MgO}$ powders with different aggregate sizes were moulded in a die with a $20 \mathrm{~mm}$ diameter. The moulding pressure was $300 \mathrm{MPa}$, and the holding time was $60 \mathrm{~s}$. After moulding, the green bodies were sintered in an air atmosphere at $1600^{\circ} \mathrm{C}$ for $2 \mathrm{~h}$.

\section{Characterisation and analysis}

The morphologies of the powders and the sintered samples were detected by using the field emission scanning electron microscopy (FE-SEM, S4800), the phase compositions of the $\mathrm{MgO}$ samples were determined using X-ray diffraction ( $\mathrm{XRD}, \mathrm{Cu} \mathrm{K} \alpha$ radiation, $30 \mathrm{kV}$ and $30 \mathrm{~mA}$ ) and the particle sizes of the $\mathrm{MgO}$ powders were measured by using a Mastersizer (Mastersizer 3000). The bulk density of the samples was measured by the Archimedes method with a medium of water, and the average of three samples for each set of data was taken.

\section{RESULTS AND DISCUSSION}

\section{Characteristics of the powder}

Figure 2 shows the relationship between the balling time and the aggregate size and the specific surface area. It was observed that the aggregate size decreased and the specific surface area increased with the increased milling time. In addition, the average aggregate sizes of the $\mathrm{MgO}$ powders prepared by the alcohol ball milling were $14.2 \mu \mathrm{m}, 7.45 \mu \mathrm{m}, 4.85 \mu \mathrm{m}, 3.74 \mu \mathrm{m}, 2.97 \mu \mathrm{m}$ and $2.13 \mu \mathrm{m}$, respectively.

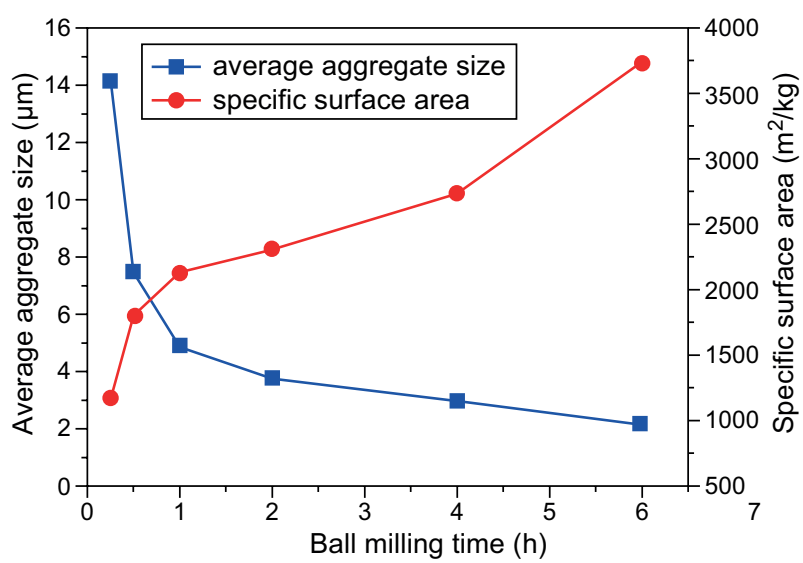

Figure 2. The relationship between the balling time and the aggregate size and the specific surface area.

Figure 3 shows the XRD patterns of the $\mathrm{MgO}$ powders with the different aggregate size. Compared with the card (00-004-0829), it could be seen that the main phase of the powder was magnesium oxide, and no impurity phase coexisted. Furthermore, the position of the peak did not shift and the width was almost the same. This indicated that the ball milling method could reduce the aggregate size, but it did not cause a lattice distortion or a lattice defect.

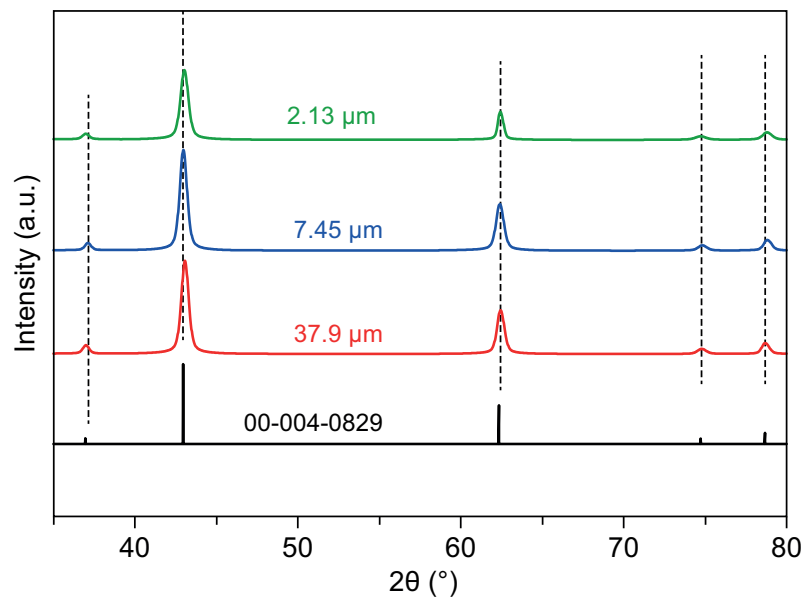

Figure 3. The XRD patterns of the $\mathrm{MgO}$ powders prepared with the alcohol ball milling. 
Figure 4 shows the micrographs of the $\mathrm{MgO}$ aggregate with the different sizes. As shown in Figure 4a, it can be seen that the $\mathrm{MgO}$ aggregate was formed by a large amount of $\mathrm{MgO}$ microcrystals. There were tiny cracks between the $\mathrm{MgO}$ microcrystals, which were caused by the departure of $\mathrm{CO}_{2}$ from the magnesite after the calcination. When the aggregate size was reduced to $7.45 \mu \mathrm{m}$ (as shown in Figure 4c), the characteristics of the $\mathrm{MgO}$ aggregate had no obvious change compared with Figure 4c. As illustrated in Figure 4c, it can be seen that more small aggregates appeared, and the shape of the aggregates tended to be circular. From Figure $4 \mathrm{~d}$, it could be understood that a large number of smaller particles agglomerated with each other and adhered to the larger particles. The ball milling broke the large aggregate and produced a large number of small aggregates, and the aggregate of all sizes were composed of $\mathrm{MgO}$ microcrystals.

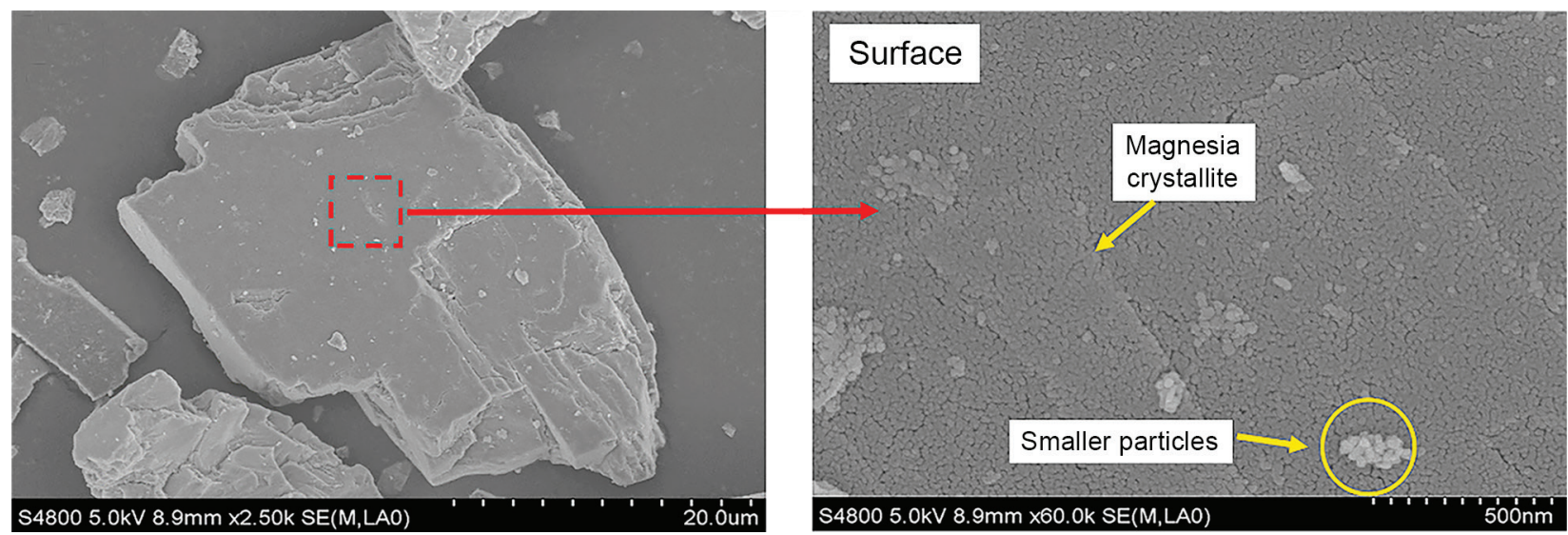

a) $37.9 \mu \mathrm{m}$

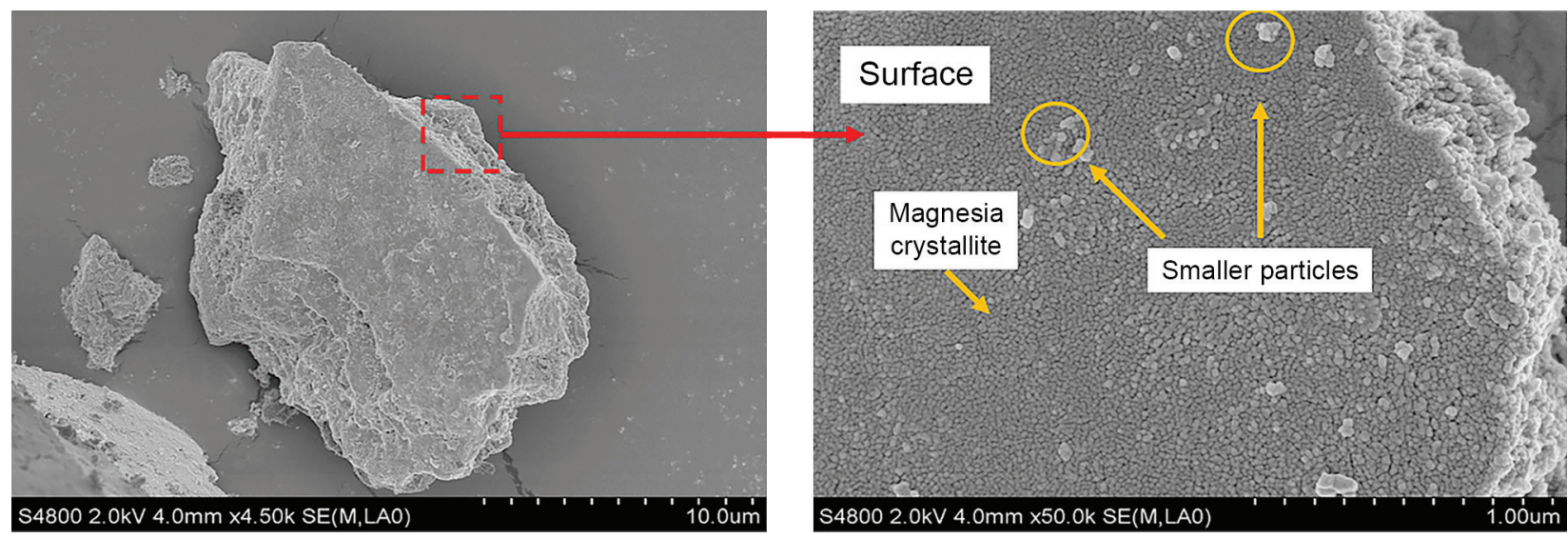

b) $7.45 \mu \mathrm{m}$

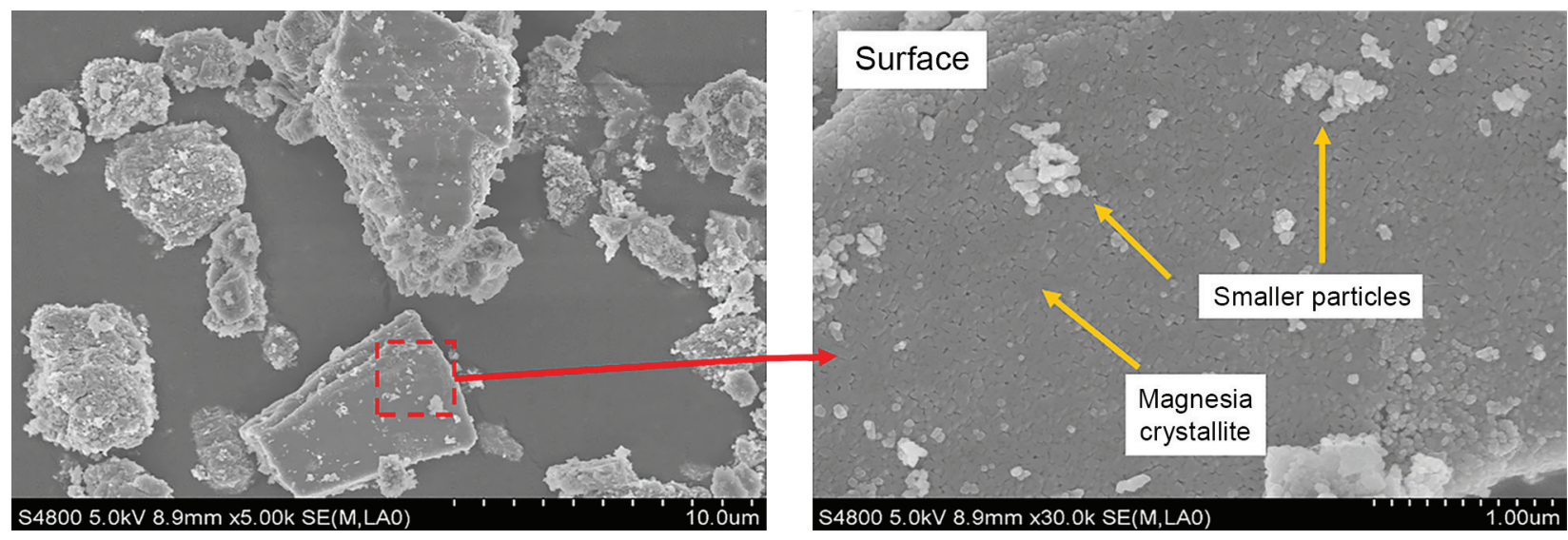

c) $4.85 \mu \mathrm{m}$

Figure 4. The SEM micrographs of the $\mathrm{MgO}$ powders with the different average aggregate sizes: a) $37.9 \mu \mathrm{m}, \mathrm{b}) 7.45 \mu \mathrm{m}, \mathrm{c}) 4.85 \mu \mathrm{m}$. (Continue on next page) 


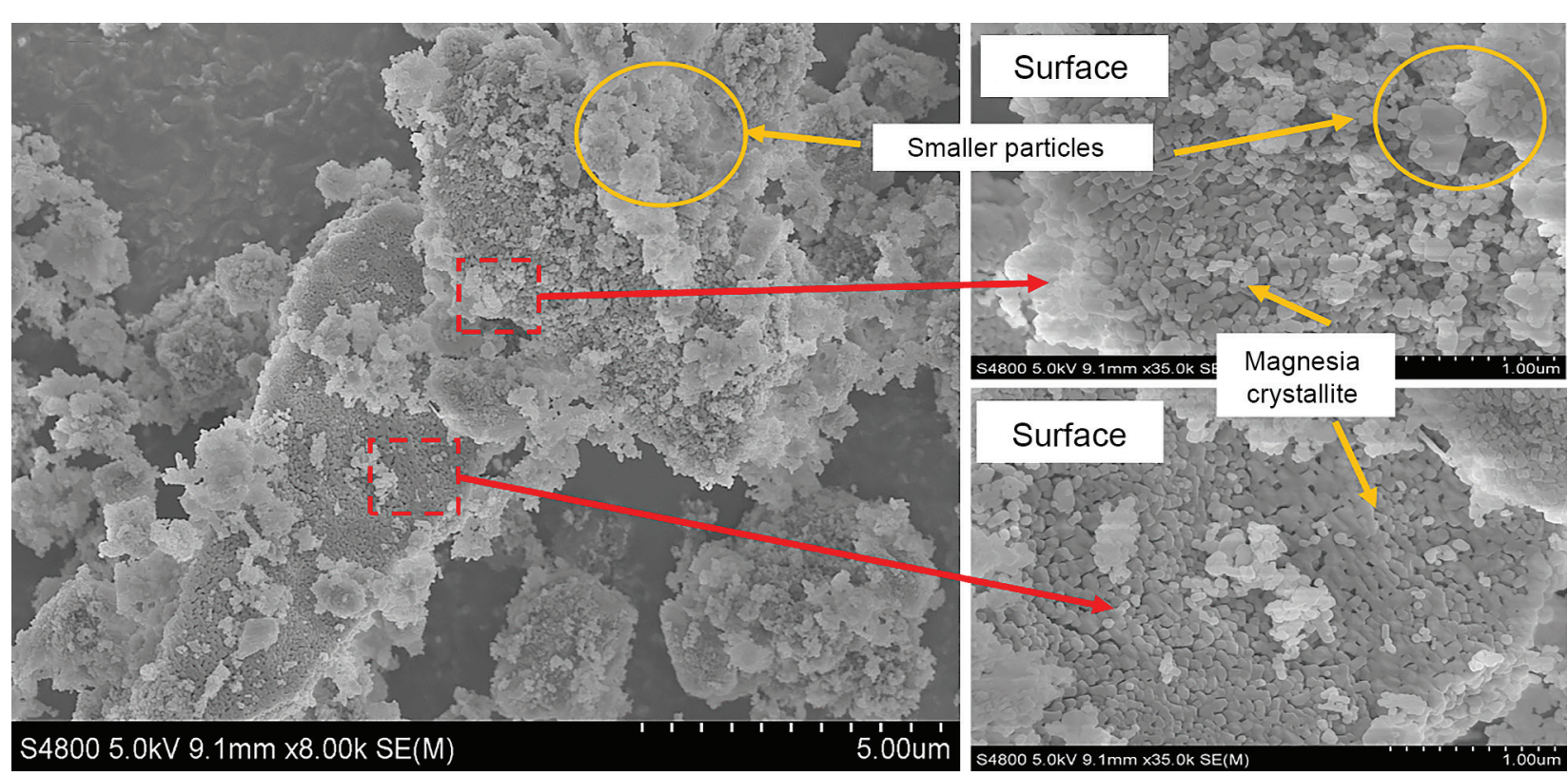

d) $2.13 \mu \mathrm{m}$

Figure 4. The SEM micrographs of the MgO powders with the different average aggregate sizes: d) $2.13 \mu \mathrm{m}$.

According to the literature research [13, 14], magnesite calcination with the accompanying loss of $\mathrm{CO}_{2}$ lead to considerable space between the $\mathrm{MgO}$ microcrystals, and the external dimensions and the rhombohedral structure was the same between the magnesite particle and the $\mathrm{MgO}$ particle (as illustrated in Figure 5). Furthermore, each $\mathrm{MgO}$ particle consisted of a large number of $\mathrm{MgO}$ microcrystals bonded together by a sintering neck and was called an $\mathrm{MgO}$ aggregate.

In the process of ball milling, the aggregates were mainly subjected to impact forces and shear forces from the agate ball, and resulting in the sintering neck, which connected the $\mathrm{MgO}$ microcrystals, to rupture and smaller aggregates to peel off from the larger aggregates (as shown in Figure 6). In particular, as shown in Figures $4 b-d$,

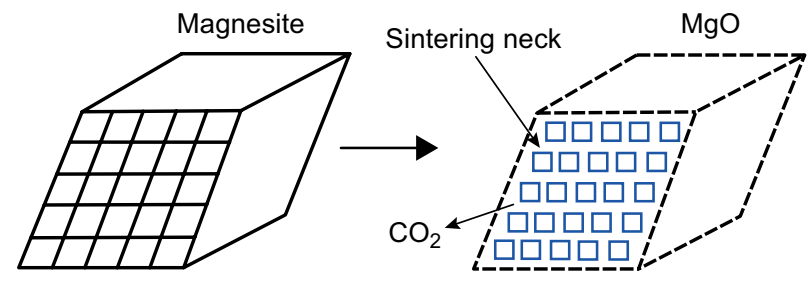

Figure 5. A schematic illustration of the aggregate occurring during the magnesite calcination.

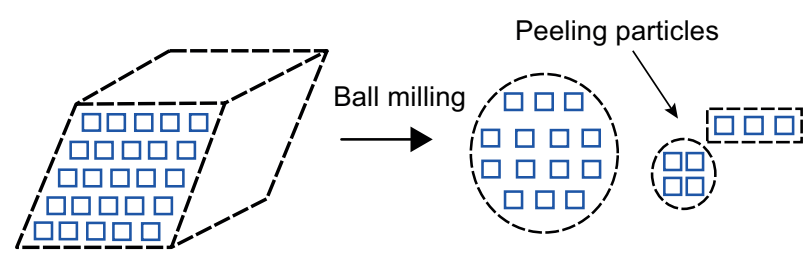

Figure 6. A schematic illustration of the small aggregate particle peeling off during the ball milling. it can be found that the stress destroyed the sintering neck between the $\mathrm{MgO}$ microcrystals, but not to the $\mathrm{MgO}$ microcrystal. As the $\mathrm{MgO}$ microcrystals were not broken, the ball milling did not bring the lattice distortions and lattice defect to the powder.

\section{Sintering ability}

Figure 7 shows the relationship between the average aggregate size and the bulk density of the $\mathrm{MgO}$ sintered at the different temperatures. From Figure 7, it can be seen that there was a significant exponential correlation between the aggregate size and the bulk density, and the bulk density of the sintered $\mathrm{MgO}$ increased with a decrease in the aggregate size. The same changing trend

Ceramics - Silikáty 64 (1) 84-91 (2020)

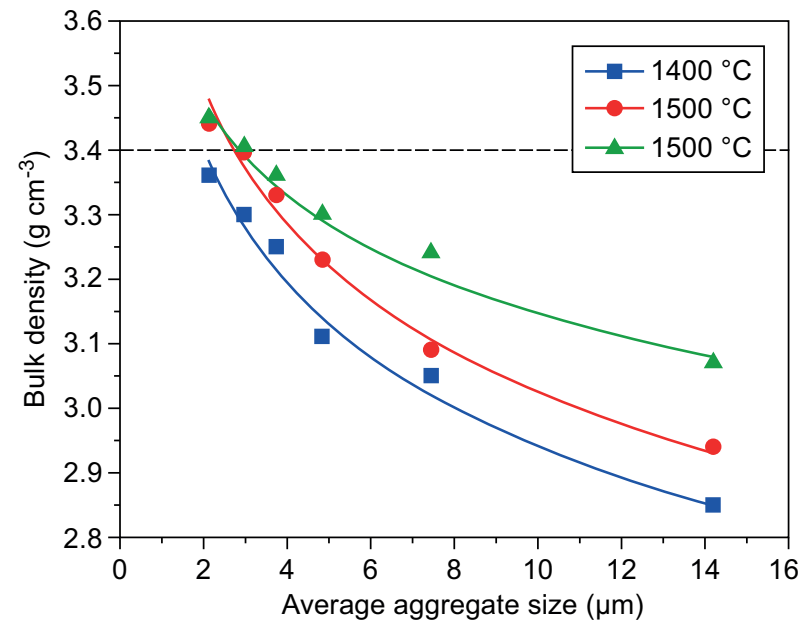

Figure 7. The changes in the bulk density of the sintered $\mathrm{MgO}$ with the average aggregate sizes. 
was visible between the aggregate size and the bulk density when reducing the sintering temperature from $1600{ }^{\circ} \mathrm{C}$ to $1400{ }^{\circ} \mathrm{C}$. Especially, if the bulk density of the sintered $\mathrm{MgO}$ was required to reach $3.40 \mathrm{~g} \cdot \mathrm{cm}^{-3}$, the average aggregate size should be less than $3 \mu \mathrm{m}$, and the sintering temperature was above $1500{ }^{\circ} \mathrm{C}$. This indicated that the size of the $\mathrm{MgO}$ aggregate has a great influence on the bulk density of the sintered $\mathrm{MgO}$.

According to the two-particle model $[15,16]$, the sintering driving force was largely determined by the neck geometry and size. The particles closely pack together after moulding, and the curved surface formed between the contact particles. The pressure difference on these curved surfaces, due to the effect of surface tension, was the initial driving force for the sintering. The pressure difference can be calculated using Equation 1.

$$
\Delta P=\gamma\left(\frac{1}{x}-\frac{1}{\rho}\right)
$$

where $\Delta P$ is the pressure difference, $\gamma$ is the powder surface tension, $x$ is the radius of the contact area and $\rho$ is the radius of the curvature for the neck. The pressure difference was inversely proportional to the radius of the curvature of the spherical particles and proportional to the surface tension of the powder. Hence, the bulk density of the samples could be enhanced when the specific surface area of the particles was increasing or the contact area between particles was larger after forming.

Besides, the aggregate is known to exert an important influence on the densification behaviour of the powder compacts [17]. For aggregates, one of the biggest problems was that the aggregates would preferentially sinter during the sintering, rather than between the aggregates. Especially, for the $\mathrm{MgO}$ aggregate, the closely packed aggregates may undergo preferential intraaggregate sintering over the interaggregate sintering and pull away from the neighbouring aggregates, leaving large pores which are difficult to close $[10,18]$. In other words, the contact area between the aggregates was an important factor affecting the densification.

Figure 8 shows the section micrographs of the green bodies formed with the different aggregate size. From Figure $8 \mathrm{a}$, it can be seen that the $\mathrm{MgO}$ aggregates with the different size were stacked together with many cracks appearing between the aggregates, and a small amount

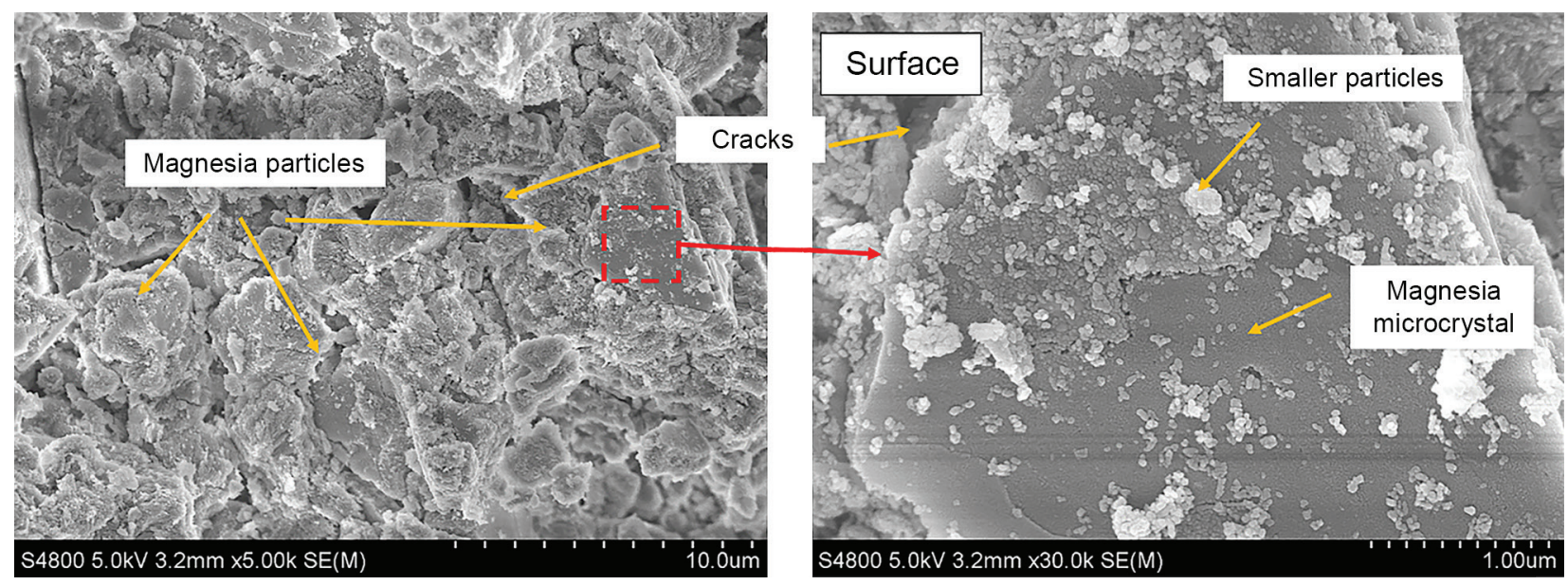

a)

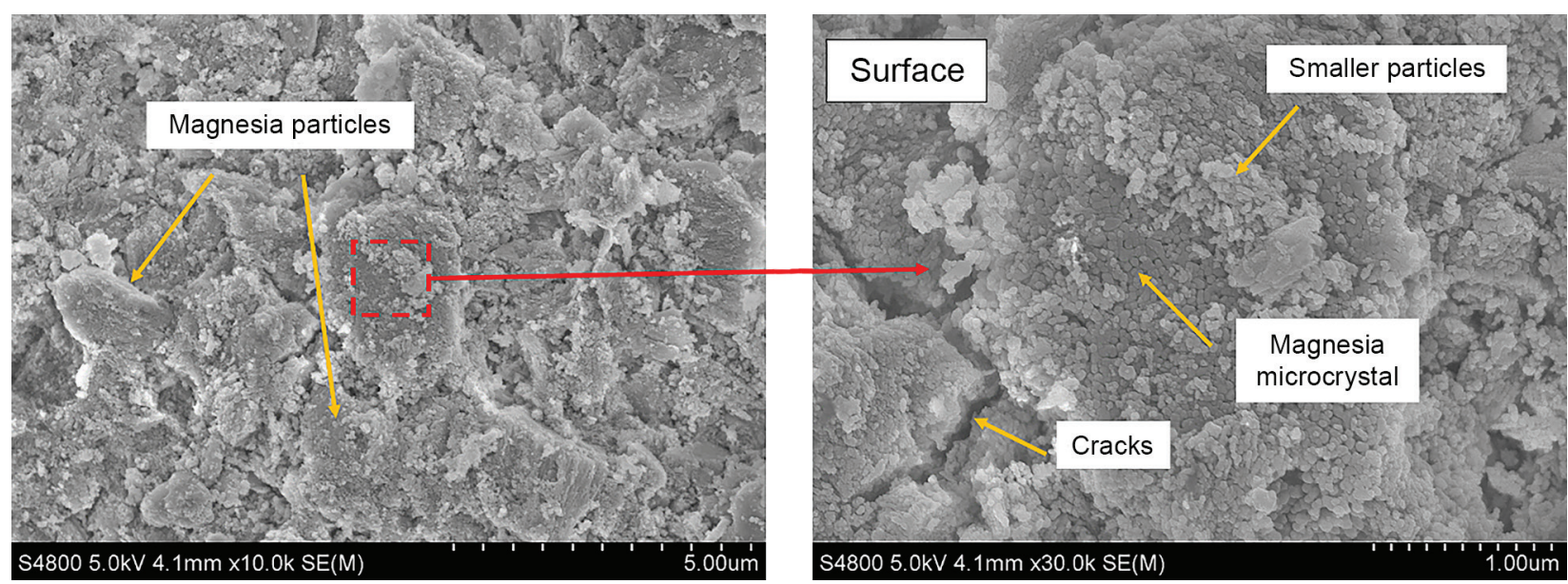

b)

Figure 8 . The section micrographs of the green bodies formed by the different aggregate sizes: a) $7.45 \mu \mathrm{m}, \mathrm{b}) 4.85 \mu \mathrm{m}$. (Continue on next page) 


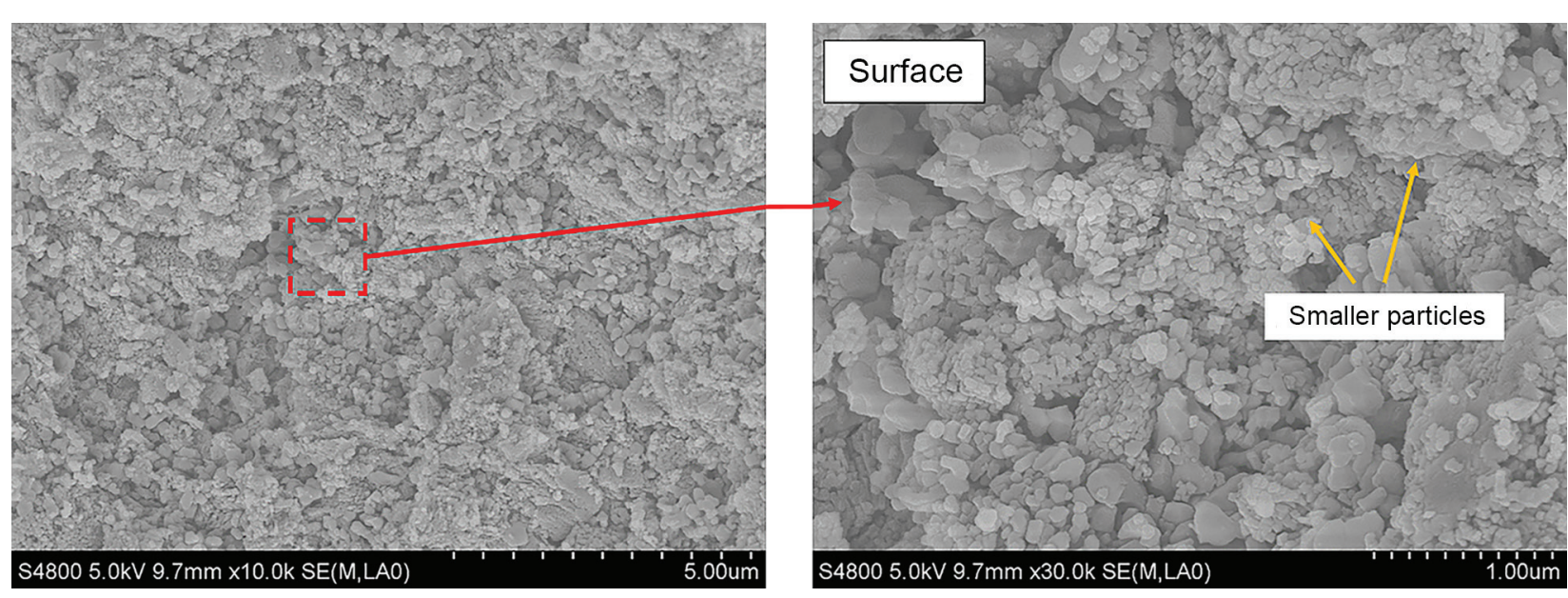

c)

Figure 8. The section micrographs of the green bodies formed by the different aggregate sizes: c) $2.13 \mu \mathrm{m}$.

of smaller aggregates were attached to the surface of the larger aggregates. Comparing with Figure 8a, the aggregates accumulated more tightly and the number of cracks decreased when the aggregate size was $4.85 \mu \mathrm{m}$ (as shown in Figure 8b). As shown in Figure 8c, it can be seen that a large number of smaller aggregates were closely packed together, and the cracks between the aggregates were not obvious. Comparing with Figure 3, it is worth noting that the aggregates are broken under the applied pressure, and the smaller aggregates filled the gap between the larger aggregates. The smaller the aggregate size, the larger the contact area after forming. Meanwhile, increasing the contact area between the aggregates was beneficial to the sintering densification process between the aggregates at high temperatures, and could avoid the formation of macropores between the aggregates. This meant that the larger contact area between the aggregates after forming was the reason that the bulk density of the sintered $\mathrm{MgO}$ increased with the decreasing aggregate sizes.

\section{The microstructure of the sintered $\mathrm{MgO}$}

Figure 9 shows the fracture surface of the sintered $\mathrm{MgO}$ prepared with the different average aggregate sizes and sintered at the different temperatures. From Figures 9a-c, it can be found that there are a lot of small grains, pores and microcracks in the sintered bodies when the temperature was $1400{ }^{\circ} \mathrm{C}$. In addition, with a decrease in the aggregate size, there were fewer defects such as pores and microcracks in the sintered samples. Similar results have been obtained when the sintering temperature was $1500^{\circ} \mathrm{C}$ (as shown in Figures 9d-f). The grain size of the sample sintered at $1400{ }^{\circ} \mathrm{C}$ was small, and the maximum grain size was only $6 \mu \mathrm{m}$. When the sintering temperature was $1500{ }^{\circ} \mathrm{C}$, the maximum size was $10 \mu \mathrm{m}$. It is worth noting that the grain size was more uniform and the grain growth was more complete when the particle size was $2.13 \mu \mathrm{m}$ and the sintering temperature was $1500{ }^{\circ} \mathrm{C}$. This indicated that the $\mathrm{MgO}$ aggregate size and sintering temperature were closely related to the grain size after the sintering. In particular, as shown in Figures 9g-i, it can be seen that the grain size increased significantly when the sintering temperature was $1600{ }^{\circ} \mathrm{C}$, and the maximum size was $40 \mu \mathrm{m}$. When the $\mathrm{MgO}$ aggregate size was large $(7.45 \mu \mathrm{m})$, there were many small grains, pores and microcracks in the sample, and the maximum grain size was only $12 \mu \mathrm{m}$. However, the grain size increased significantly when increasing the particle size of the powder to $4.85 \mu \mathrm{m}$, and the maximum grain size was over $40 \mu \mathrm{m}$. Comparing Figure 9h with Figure 9i, the difference is that the sample prepared with the larger $\mathrm{MgO}$ aggregate size had some large pores and microcracks at the grain boundary. It shows that the samples prepared from the fine aggregates had fewer defects after the sintering, such as pores, microcracks, and the temperature had a significant effect on increasing the grain size.

During the sintering process, the agglomerate of the particles increased when increasing the grain growth, the stomatal coordination number decreased, and the bulk density of the samples was greatly increased [19]. When increasing the sintering time, the $\mathrm{MgO}$ particles began to bond in the form of the neck, thus it expanded, and then the processes of the grain boundary migration and grain growth carried out simultaneously. The movement of the grain boundaries directly affected the distribution of the pores under the action of the interfacial energy. The grain boundary crossed the pores and wrapped the pores inside the grain when the grain boundary had enough interface energy. If the size of the pore was large, the pores inside the grain blocked the movement of the grain boundaries and the grain boundary would stop moving or continue to move for a short distance. Then, large pores appeared between two or three grain boundaries. Namely, the larger size aggregates required more external energy to achieve a denser state. Thus, there were a lot of pores and microcracks in the sintered $\mathrm{MgO}$ at low temperatures 


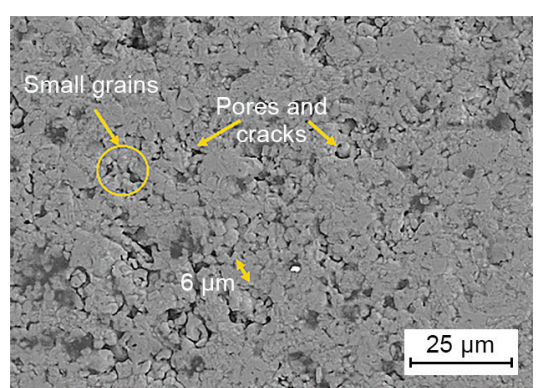

a) $1400{ }^{\circ} \mathrm{C} / 7.45 \mu \mathrm{m}$

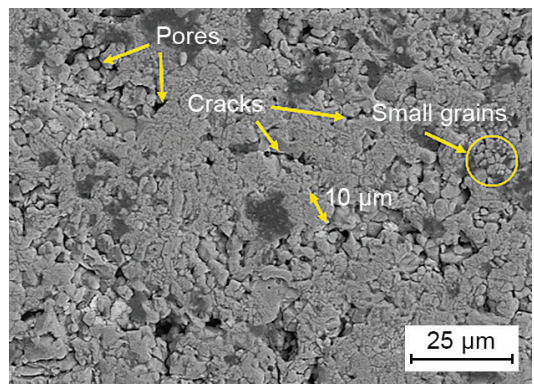

d) $1500{ }^{\circ} \mathrm{C} / 7.45 \mu \mathrm{m}$

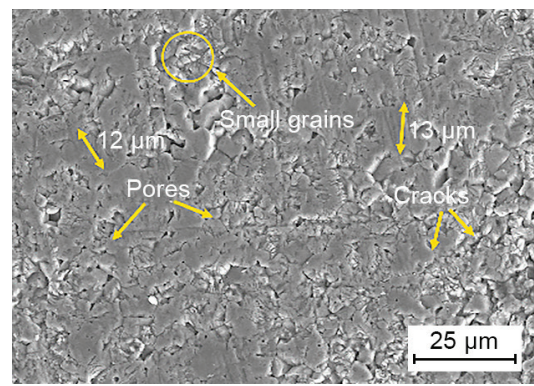

g) $1600{ }^{\circ} \mathrm{C} / 7.45 \mu \mathrm{m}$

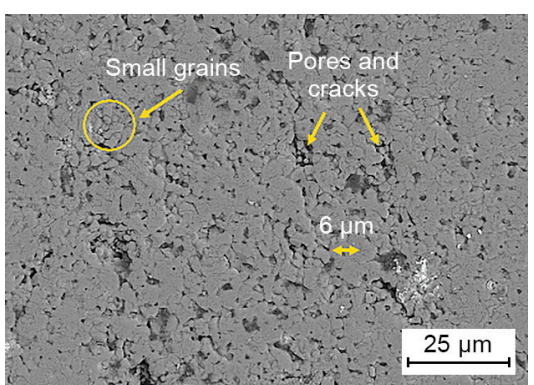

b) $1400{ }^{\circ} \mathrm{C} / 4.85 \mu \mathrm{m}$

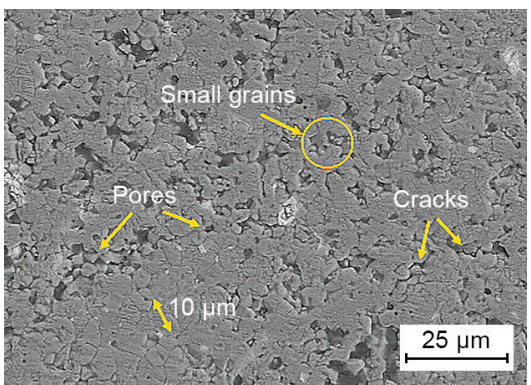

e) $1500^{\circ} \mathrm{C} / 4.85 \mu \mathrm{m}$

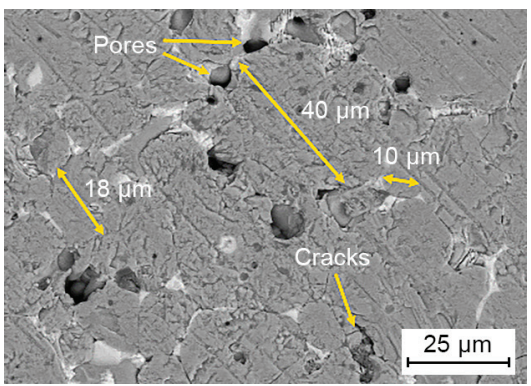

h) $1600{ }^{\circ} \mathrm{C} / 4.85 \mu \mathrm{m}$

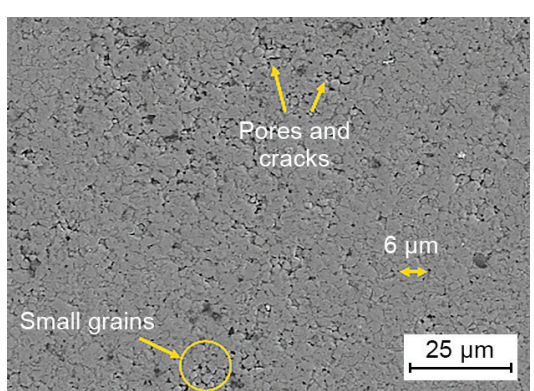

c) $1400{ }^{\circ} \mathrm{C} / 2.13 \mu \mathrm{m}$

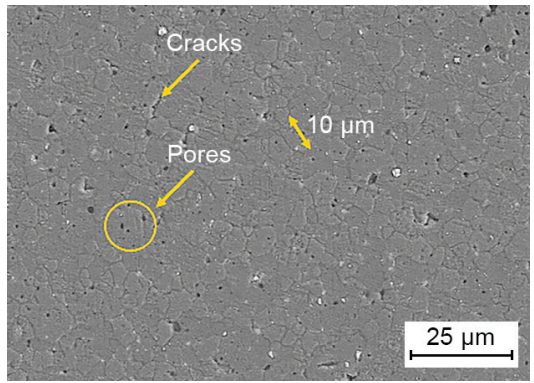

f) $1500{ }^{\circ} \mathrm{C} / 2.13 \mu \mathrm{m}$

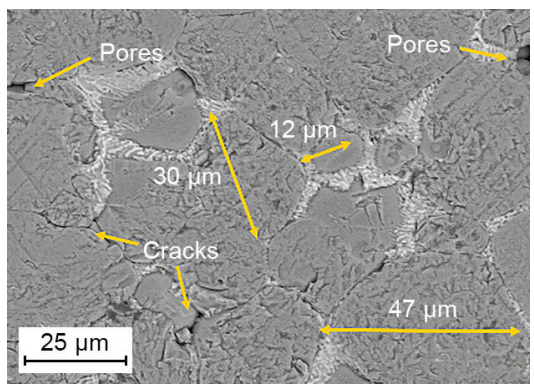

i) $1600{ }^{\circ} \mathrm{C} / 2.13 \mu \mathrm{m}$

Figure 9. The SEM micrographs of the sintered $\mathrm{MgO}$ which was prepared with a different average size at: $\left.1400{ }^{\circ} \mathrm{C}-\mathrm{a}\right) 7.45 \mu \mathrm{m}$, b) $4.85 \mu \mathrm{m}$ and c) $2.13 \mu \mathrm{m} ; 1500{ }^{\circ} \mathrm{C}-$ d) $7.45 \mu \mathrm{m}$, e) $4.85 \mu \mathrm{m}$ and f) $\left.\left.2.13 \mu \mathrm{m} ; 1600{ }^{\circ} \mathrm{C}-\mathrm{g}\right) 7.45 \mu \mathrm{m}, \mathrm{h}\right) 4.85 \mu \mathrm{m}$ and i) $2.13 \mu \mathrm{m}$.

$\left(1400{ }^{\circ} \mathrm{C}\right.$ and $\left.1500{ }^{\circ} \mathrm{C}\right)$ due to the smaller driving force of the sintering. At $1600{ }^{\circ} \mathrm{C}$, due to the movement of the grain boundaries, a large number of small pores was discharged or migrated to the grain boundaries to form larger pores and several small grains merged into a large one. This explained the reason of the result that the bulk density of the samples was similar when the average $\mathrm{MgO}$ aggregate size was less than $3 \mu \mathrm{m}$ when the sintering temperatures were $1500{ }^{\circ} \mathrm{C}$ and $1600{ }^{\circ} \mathrm{C}$, but the grain size of sintered $\mathrm{MgO}$ was quite different.

\section{CONCLUSIONS}

The effect of the $\mathrm{MgO}$ aggregate size on the $\mathrm{MgO}$ sintering was studied, and the results can be concluded as follows:

- The ball milling method can reduce the $\mathrm{MgO}$ aggregate sizes and produce more small particles, and it does not bring lattice distortion or lattice defects to the powder.
- There was a significant exponential correlation between the average aggregate size and bulk density, and the bulk density increased with the decreasing average aggregate size. Furthermore, the average aggregate size should be less than $3 \mu \mathrm{m}$ and the sintering temperature should be above $1500{ }^{\circ} \mathrm{C}$ when the bulk density of the sintered $\mathrm{MgO}$ was required to reach $3.40 \mathrm{~g} \cdot \mathrm{cm}^{-3}$.

- The sintered $\mathrm{MgO}$ prepared from the small aggregate size had fewer defects after sintering, such as pores and microcracks, and the sintering temperature had a significant effect on increasing the grain size. In particular, the maximum grain size was more than $40 \mu \mathrm{m}$ when the sintering temperature was $1600^{\circ} \mathrm{C}$.

\section{Acknowledgments}

This work is supported by the National Natural Science Foundation of China (No.51874083, and No.51404056). 


\section{REFERENCES}

1. Han B.Q., Li Y.S., Guo C.C., Li N, Chen F. Y. (2007): Sintering of MgO-based refractories with added $\mathrm{WO}_{3}$. Ceramics International, 33, 1563-1567. doi: 10.1016/j. ceramint.2006.07.014

2. Jin E.D., Yu J.K., Wen T.P., Tian C., Liu Z.Y., Ma B.Y., Mao F.X., Yuan L. (2019): Effects of the molding method and blank size of green body on the sintering densification of magnesia. Materials, 12, 647. doi: 10.3390/ma12040647

3. Yang W.Z. (2003): Operation technique of high temperature oil shaft kiln for calcination of magnesite. Bulletin of the Chinese Ceramic Society, 4, 89-93. (In Chinese)

4. Chen Z.Y., Li H.X. (2005): Comprehensive utilization of natural magnesium-containing resources and development of MgO-based refractories. China's Refractories, 14, 3-15.

5. Pampuch R., Librant Z., Piekarczyk J. (1975): Texture and sinterability of $\mathrm{MgO}$ powders. Ceramurgia International, 1, 14-18. doi: 10.1016/0390-5519(75)90033-2

6. Alvarado E., Torres-Martinez L.M., Fuentes A.F., Quintana P. (2000): Preparation and characterization of $\mathrm{MgO}$ powders obtained from different magnesium salts and the mineral dolomite. Polyhedron, 19, 2345-2351. doi: 10.1016/S02775387(00)00570-2

7. Xu X.W., Rao D.S. (1988): Influence of pseudomorph of magnesite on densification of $\mathrm{MgO}$ sintering. Journal of the Chinese Ceramic Society, 16, 244-251. (in Chinese)

8. Li N. (1989): Formation, compressibility and sintering of aggregated $\mathrm{MgO}$ powder. Journal of Materials Science, 24, 485-492. doi: 10.1007/bf01107431

9. Li H., Yu J.K. (2009): Influence of light calcining hydration of magnesite on $\mathrm{MgO}$ sintering. China's Refractories, 18 , 23-28.
10. Rhodes W.H. (1981): Agglomerate and particle size effects on sintering yttria-stabilized zirconia. Journal of the American Ceramic Society, 64, 19-22. doi: 10.1111/j.11512916.1981.tb09552.x

11. Ma J., Lim L. C. (2002): Effect of particle size distribution on sintering of agglomerate-free submicron alumina powder compacts. Journal of the European Ceramic Society, 22, 2197-2208. doi: 10.1016/s0955-2219(02)00009-2

12. Lange F. F. (1984): Sinterability of agglomerated powders. Journal of the American Ceramic Society, 67, 83-89. doi: 10.1111/j.1151-2916.1984.tb09620.x

13. Bittencourt L. (1995). Densification and grain growth of a refractory grade magnesia derived from magnesite. University of Missouri, Columbia.

14. Eubank W. R. (2006): Calcination studies of magnesium oxide. Journal of the American Ceramic Society, 34, 225-229. doi: 10.1111/j.1151-2916.1951.tb11644.x

15. Kang S. J. L. (2004). Sintering: densification, grain growth and microstructure. $1^{\text {st }}$ ed. Elsevier.

16. Gupta T. K., Bechtold J. H., Kuznicki R. C., Cadoff L. H., Rossing B. R. (1977): Stabilization of tetragonal phase in polycrystalline zirconia. Journal of Materials Science, 12, 2421-2426. doi: 10.1007/bf00553928

17. Kimura T., Matsuda Y., Oda M., Yamaguchi T. (1987): Effects of agglomerates on the sintering of alpha- $\mathrm{Al}_{2} \mathrm{O}_{3}$. Ceramics International, 13, 27-34. doi: 10.1016/0272-8842 (87) $90035-6$

18. Li N. (1994): Sintering mechanism and kinetic models of aggregated $\mathrm{MgO}$ powder compact. Journal of the Chinese Ceramic Society, 22, 77-84. (in Chinese)

19. Varela J. A., Whittemore O. J., Longo E. (1990): Pore size evolution during sintering of ceramic oxides. Ceramics International, 16, 177-189. doi: 10.1016/02728842(90)90053-i 